Article

\title{
Dressing a Demanding Body to Fit In: Clean and Decent with Ostomy or Chronic Skin Disease
}

\author{
Kirsi Laitala * and Ingun Grimstad Klepp \\ Consumption Research Norway-SIFO, Oslo Metropolitan University, 0130 Oslo, Norway; E-Mails: kirsi.laitala@oslomet.no \\ (K.L.), ingun.g.klepp@oslomet.no (I.G.K.) \\ * Corresponding author
}

Submitted: 17 August 2018 | Accepted: 1 October 2018 | Published: 31 January 2019

\begin{abstract}
This article discusses what kind of strategies people with a stoma or various chronic skin conditions, such as psoriasis or atopic dermatitis, use to find clothes that fit and enable them to fit in. Based on qualitative interviews in Norway, we study how they manage to dress with a demanding body, a poor market and limited economic resources. This includes describing how purchases take place, which clothes fit, how much clothing is needed, and which laundry practices are used. Their main strategy was to reduce the requirements for their own appearance rather than to cleanliness and body odours. If they were unable to appear appropriately dressed, as a minimum odourless and stain free, they reduced their participation in social life.
\end{abstract}

\section{Keywords}

apparel; cleanliness; clothing; consumption; dermatitis; disability; laundry; odour; ostomy; psoriasis

\section{Issue}

This article is part of the issue "People with Disabilities: The Overlooked Consumers", edited by Anita Borch and Kirsi Laitala (Consumption Research Norway-SIFO, Norway).

(C) 2019 by the authors; licensee Cogitatio (Lisbon, Portugal). This article is licensed under a Creative Commons Attribution 4.0 International License (CC BY).

\section{Introduction}

We all have to be dressed; however, some bodies are more difficult to dress than others. Having clothes that fit the body as well as the occasion are central to being able to take part in social activities. About $15 \%$ of the population worldwide lives with disabilities, and that number is increasing due to an ageing population (WHO, 2011). Having a disability can increase the chances of experiencing physical restrictions and social barriers in everyday life. Here, we use the word 'disability' in its wide and simplified meaning, as any "permanent injury or chronic illness" (Grue, 2015, p. 27).

Previous studies have shown that the clothing market for users with disabilities is poor, and in some cases almost non-existent, especially for consumer groups with physical disabilities (Bjerck, Klepp, \& Skoland, 2014; Freeman, Kaiser, \& Wingate, 1985; Thorén, 1996). Prod- ucts poorly designed and not fitted properly for the wearer not only can make life difficult but also lead to unpleasant or even painful and unhealthy conditions. Mass produced apparel available in clothing stores is designed for the non-disabled user and is difficult to adjust to special needs; thus, it seldom satisfies the technical and social needs of many disabled users (Kabel, Dimka, \& McBee-Black, 2017; Kratz et al., 1997). Clothes are important for self-esteem and influence the opinions of others (Kaiser, 1997). Indeed, the appearance of clothing is important; but equally important is that it must not be dirty or smelly (Klepp, 2007).

The purpose of clothing is to conceal the body and make it socially acceptable (Lamb \& Kallal, 1992). More, however, is required from clothes to conceal a body that does not conform to current beauty ideals, than to conceal an "ideal body" (Entwistle, 2000). Deviating bodies are thus both physically and socially harder to dress. Pre- 
vious research has shown that consumers with disabilities use two main strategies. In some occasions, they dress so that the disability is minimally visible, while in other contexts, they dress so that the body functions optimally (Bjerck et al., 2014). These two strategies are often contradictory, and the one chosen depends on the occasion. It is also an important norm for people with disabilities to accept their bodies as they are, which contrasts with the norm of wishing to normalize the body (Klepp \& Rysst, 2017).

People with disabilities have lower average incomes and may have extra costs resulting from the disability (WHO, 2011, p. 10). This applies also to clothing: people with some disabilities require more resources to achieve the same level of appropriate dressing as non-disabled people. Because of higher costs, people with disabilities are likely to be poorer than non-disabled people with similar incomes (WHO, 2011).

Previous studies on clothing consumption do not combine this economic aspect with disability and social inclusion in a way we want to do. Many of the studies have also focused on physical disabilities, especially wheelchair users, and we want to study consumer groups with a more common diagnosis. In this article, we focus on two conditions that are among those that cause the most extra clothing costs in Norway: psoriasis and other chronic skin conditions, and people with ostomy. This article discusses what kinds of strategies people with these disabilities use to find clothes that fit and enable them to fit in. Specifically, how do they manage to dress to fit in with a more demanding body, a poor marked, and limited economic resources.

We will first give the theoretical starting point for our research as well as some background information on the consumer groups we study. This is followed by a section on our methodology, which included qualitative interviews conducted in Norway in 2018. The results section shows how the disabilities affect our informants' everyday life, their clothing acquisition and maintenance practices and the economic aspect of their clothing consumption. This is followed by a discussion on how these aspects are managed and which strategies are chosen to fit in. We conclude with a discussion about the consequences of our findings for social inclusion. We then give suggestions for future research areas.

\section{Background}

In Norway, people that have extraordinary clothing costs due to illness or medical condition are entitled to receive a monthly support to cover these expenses. To date, qualifying for this support means that the expenses have to be documented for a minimum of three months and have to exceed a specified sum compared to normal costs ${ }^{1}$ (NAV, 2018). This documentation practice has been criticised (Proba, 2017). Some of the expenses are difficult to document through receipts, such as the additional wear and tear of clothing or the need for extra laundering. For many individuals with various medical diagnoses, it is also difficult to collect receipts and to systematically document the extra costs over such a long period of time. It also creates the potential for inequality based on income, since those with low income cannot necessarily afford the clothing they would need to buy to qualify for the support, while those with a higher income can buy all the necessary products and easily document the extra costs (Proba, 2017). Therefore, this system is now under evaluation to see if the application and qualification process can be simplified. This article is based on a project that evaluated the extra costs for some diagnosis groups that commonly receive the support (Roos, Laitala, Klepp, Austgulen, \& Borgeraas, 2018). The groups were chosen based on statistics on diagnosis codes that commonly receive support for extra clothing costs.

\section{Theoretical Framework}

Disability studies have gone through a shift in focus from medical model towards social constructions (Berghs, Atkin, Graham, Hatton, \& Thomas, 2016; Grue, 2015). The medical model reduces all the aspects of disability to bodily impairment, which requires medical treatment. The social model gives a voice to the people with disabilities. People with disabilities are seen as a politically and economically oppressed class in a Marxist theoretical framework (Grue, 2015). However, Tom Shakespeare, a sociologist working in disability studies, suggests that rather than dichotomizing these opposing models, disability should be understood as multi-factorial, including biological, psychological and social aspects; thus, disability does not just result from social oppression. He proposes that "[w]e need to take account of all the factors, and intervene at all the different levels to benefit and include disabled people" (Shakespeare, 2018, p. 21). We follow Shakespeare's recommendation, and use perspectives that include biological, psychological and social aspects of disability in our research.

Disabilities and various medical diagnoses themselves can make it more difficult for people with disabilities to be socially accepted. This is in line with Goffman's (1986) theory of stigma, in which the stigmatised attribute causes the person to be looked upon as abnormal and then rejected. Goffman discusses how a person with a stigma tries to control the information about it. He uses the word 'passing' to describe a person who manages to hide the stigma and, thus, pass as a person without the stigma. Goffman does not discuss clothing as a technique of information control, but clothing can be used to facilitate acceptance (Entwistle, 2000). Not only is the body itself subject to taboo but so too are the body's secretions (Douglas, 1984). Such substances as urine, sweat, mucus, tears, breastmilk, menstruation blood, faeces, discharges, pus, dandruff and semen are often considered culturally problematic (Mauss, 1979). Clothes constantly

\footnotetext{
${ }^{1}$ Currently minimum limit is NOK 678/month, about EUR 71 or 84 US dollars (exchange rate of September 2018).
} 
become 'contaminated' by them, and this contamination may be visible in the form of stains, may be invisible, such as bacteria or may be sensed through other means, such as smell or touch. Today, bodily malodours are especially considered socially stigmatising (Classen, Howes, \& Synnott, 1994; Frykman \& Löfgren, 1994). Being unable to control the body's fluids is a stigma affecting the way a person is perceived.

Entwistle (2000) argues that clothes act as the body's boundary to the world. They constitute a border between the individual and society. To maintain a clear boundary, we must not only have clothes but clean ones (Klepp, 2003, 2005; Shove, 2003). Cleanliness norms for clothes are complex and vary with age, gender and class. Rules attached to the cleanliness of women's clothes are the strictest (Klepp, 2007). How much is demanded from clothes, or how strict the clothing norms are, depends both on how much the body is subject to taboos and on the social situation (Klepp, 2007). To some extent, these norms seem to conform to the norms connected with decency. This is understandable, since both are related to the way the body is made socially acceptable. Lurie writes that cleanliness "is usually regarded as a sign of respectability or at least of self-respect" (Lurie, 1981, p. 13). For example, one of the aims within charity work is to provide people with clean clothes because that contributes to returning dignity to the recipients (Larssen \& Bry, 2001).

Various disabilities and conditions require extra consideration for selecting clothing, and cause additional costs related to wear and tear. Below, we give a short background for the disabilities this article focuses on.

\subsection{Psoriasis, Atopic Dermatitis and Other Skin Diseases}

Psoriasis and atopic dermatitis are chronic inflammatory skin diseases. In both conditions, skin may appear red, inflamed, peeling, cracked, blistered or pus-filled, but psoriasis has the additional characteristic of a thick patch of white scales (WHO, 2016). Lesions cause itching, stinging and pain. Both skin conditions are common (Siegfried \& Hebert, 2015; WHO, 2016), and atopic dermatitis affects up to $20 \%$ of children and between $2.1 \%$ and $4.9 \%$ of adults worldwide (Barbarot et al., 2018; Nutten, 2015).

Some individuals with psoriasis develop chronic, inflammatory arthritis (psoriatic arthritis), which leads to pain, swelling and stiffness in joints and tendons. The disease can affect the hips, shoulder and elbows, as well as small joints such as those in fingers. Psoriasis has also other significant comorbidities, including cardiovascular diseases, metabolic syndrome, inflammatory bowel disease and depression (WHO, 2016).

Hidradenitis suppurativa (HS) is another chronic skin condition, which is an inflammation of the sweat glands. HS can become a painful, long-term skin condition that causes abscesses and scarring on the skin. An outbreak causes pain, fluid bumps and bad odours.
Chronic urticarial (CU) is also called 'hives' or 'nettle rash'. CU is an allergic condition of the skin, which is characterized by a skin rash, notable for its dark-red, raised, and itchy bumps that may also burn or sting (Sachdeva, Gupta, Amin, \& Tahseen, 2011). It affects $15-20 \%$ of the global population once or more during a lifetime. In most cases, chronic hives occur for $1-5$ years, but it may last for several years. Psoriasis, HS and CU are more common in women than men.

Several studies have reported that psoriasis has a negative impact on quality of life (QoL; Augustin, Kruger, Radtke, Schwippl, \& Reich, 2008; de Korte, Sprangers, Mombers, \& Bos, 2004; Moradi et al., 2015; Weiss et al., 2002; Zachariae et al., 2002). Based on a large European survey among psoriasis patients in seven countries, Dubertret et al. (2006) showed that the biggest problem among these patients was the choice of clothes, followed by an increased need for body wash and an increased amount of doing laundry and changing clothes. Over $40 \%$ of respondents reported that these activities were influenced by their psoriasis to a large or very large extent. Those with a larger proportion of the body affected by psoriasis reported major problems.

Some scientific articles discuss the extra expenses associated with psoriasis and atopic eczema (Dubertret et al., 2006; Navarini et al., 2010). Some ointments increase the need for laundry, new clothes and new bedding more than other ointments (Poyner, Wall, Adnitt, \& Menday, 1999). A study of German psoriasis patients showed that increased laundry costs were 28 euros $^{2}$ per year, but the study does not indicate the costs included in the estimate (Sohn et al., 2006). It has also been reported that the time spent on the treatment of psoriasis and on doing more laundry add significant cost to patients when calculating cost in terms of time lost (Mustonen, Mattila, Leino, Koulu, \& Tuominen, 2014). Most studies focus on treatment costs, and they rarely include increased clothing costs (e.g., Navarini et al., 2010); if they are included, they are given together with other costs (Berger, Ehlken, Kugland, \& Augustin, 2005). Many calculate costs at the national level rather than at the individual level (e.g., Ellis et al., 2002).

\subsection{Ostomy}

A stoma is an artificial opening in the abdominal wall. The end of the small or large intestine, colon or ureter is connected to the surface of the abdomen to provide an alternative channel for faeces to leave the body. People with ostomies have pouches attached to their sides where the bowel contents are collected. The most common underlying conditions resulting in ostomy surgery are cancer in the colon or bladder and inflammatory bowel diseases (IBD), such as ulcerative colitis or Crohn's disease (Brown \& Randle, 2005). The stoma opening connected to the small intestine is called an ileostomy, while in a colostomy, the soma is connected to the large intes-

\footnotetext{
2 Equivalent to about 33 US dollars in January 2006.
} 
tine or colon. A stoma that diverts the urea is called an urostomy. In addition to health problems connected to the underlying causes for ostomy, about half of the people who had had ostomy operation also develop hernias (Cima, 2018).

Numerous studies on life quality after an ostomy operation point out several potential problems. Patients reported that the operation altered their body image, had a negative effect on their social life, sex lives, limited their choice of occupations because of the possibility of leakage, and forced them to adjust their diet and clothing choices (Brown \& Randle, 2005; Gooszen, Geelkerken, Hermans, Lagaay, \& Gooszen, 2000). None of the studies given in literature review by Brown and Randle (2005) on living with a stoma focused specifically on clothing, including the maintenance and economic aspects. Clothes should support the pouch, while not putting too much pressure on it (Proena \& Rydelius, 2015). The studies that do focus on extra costs are related to the direct costs of the ostomy equipment (Coons, Chongpison, Wendel, Grant, \& Krouse, 2007); they do not include the extra costs related to leakages and laundering.

\section{Method}

We contacted two patient organizations, the Psoriasis and Eczema Association (PEF) and the Norwegian Association for Stoma, Reservoir and Gastrointestinal Cancer (Norilco), who recruited informants to our study. In addition, one informant was recruited through private networks. We asked the organizations to find up to five members who present a variation in the diagnosis groups which the organizations represent. The organizations arranged contact with our informants so that we did not have to collect or store any personally identifiable information in order to ensure complete anonymization of the data. We originally wished to collect data through group interviews. This was possible with the PEF members, but because of the busy schedules of our informants from Norilco, those interviews were conducted individually.

PEF facilitated the group interview by inviting five of their members to the meeting, four women and one man, who represented different but related diagnoses. The man had chronic urticaria, a diagnosis that has fewer consequences for clothes; therefore, he had less to say. The four women presented the following diagnosis: psoriasis, psoriasis arthritis, atopic dermatitis and allergies, and HS. All of the informants in this group were around middle aged, in their forties and fifties, except for the person with psoriasis arthritis who was already retired. The informants showed a great willingness and ability to be open and honest about intimate and even unpleasant topics. This interview took place at PEF's main office and lasted two hours.

We interviewed individually three people with ostomies who represent rather different groups. The first was a young woman in her early twenties who had a tem- porary stoma due to Crohn's disease. She had had the stoma for only a few years, and was waiting for her operation to have a permanent colostomy. Even though she was a relatively new stoma user, she had more knowledge about the topic because she had participated and talked with others in a similar situation in a different project. Our second interview was with a retired man who had two stomas, ureostomy and ileostomy, which is rather unusual. He had had them for a long time due to cancer, but he had learned to live with them. He pointed out that the situation was better now than when he was living with the painful cancer. These two interviews were conducted at the university and took just over an hour.

The third interview was conducted by phone and took a little over 20 minutes. The informant was a woman in her early fifties; she had had a stoma for over 30 years due to Crohn's disease. She was working full time and experienced less stoma-related problems than the other two informants. This interview was based on the notes from the first one, and we discussed on how her experiences were similar or different compared to our first informant.

Discussions during these qualitative interviews were structured around clothing practices, and we used an interview guide listing all the basic clothing and textile items that can be affected by the conditions, including shoes and bedlinen. We asked the informants to describe their clothing acquisition, how they used the clothes during various occasions, how often they washed them and with what temperature and how often various items had to be replaced due to wear and tear. We also asked specifically which clothing consumption areas they considered to be problematic, and if there had been any changes as their condition developed. The aim was to find out which additional clothing costs the informants had when compared with non-disabled users. The interviews were conducted during May and June 2018 in Oslo, Norway, and all our informants live within a $70 \mathrm{~km}$ radius from the city. We recorded the conversations, and after the meetings, the interviewers wrote summaries. These were sent back to the associations so that the informants had the chance to comment. We analysed the data by organizing the results based on clothing and textile types and the occasions of use; we then compared the experiences (see more details in Roos et al., 2018). This way, we found which areas were problematic to our informants. These themes are discussed by topic in the results section of this article. For this article, quotations are translated from Norwegian to English by the authors.

We have chosen to collect and analyse material as examples of the problems and solutions that the diagnoses give and not to focus on the individual informants. Therefore, the informants are not presented with their name and age in the text. Where we believe personal information such as gender is relevant to the interpretation, we have mentioned it with a citation. This study is exploratory in nature and based on a small number of respondents recruited by patient organizations; there- 
fore, the results cannot be generalized to apply to all people with similar conditions. It does, however, provide a starting point for discussing topics that have not yet been researched.

\section{Results}

\subsection{Clothing and Acquisition}

The disabilities may affect what kind of clothing fit and how purchases can take place. First, we look at the purchase situation and then describe how the disabilities affect which clothes are suitable.

\subsubsection{Purchase Situation}

Clothing production today is dominated by ready-made manufacturing. This means that clothes are not adapted to individual users but are made to fit standardized measures. They can be bought in stores or through mail order; both options provide the possibility to try them on. Trying on the clothes ensures that the clothes fit the body and that they feel comfortable to wear, but it also ensures that the buyers like the way they look when wearing the garment. The option of trying on clothing was not available for many of our informants.

Informants with psoriasis worry that different substances will be left in the clothes after they try them on. One informant said:

You get so tired and just despair, because you cannot go in and try on clothes that someone else might try after you. There hangs a kilo of dandruff and blood stains and a bit of pus and dirt...[and] then you may have a bloody back that seeps out.

This applies to underwear, jeans, shirts and blouses. One of the informants says she has done a lot of mistake purchases:

When your skin looks like a meat cake, you do not want to go into a fitting room and put on clothes that others may wear afterwards. Then I take it on me [she shows how she puts the clothing item in front of her body to evaluate fit], and then it looks like it fits, but then it does not.

For ostomy poach users, trying on clothes can be difficult because they are afraid of leaks and also that the poach may be seen:

The salespeople are trying to assist and come in and help. I do not think that is okay because I'm so afraid that they'll see the pouch and so if they know what the ostomy is, they'll say, 'No you are not allowed to try it on because it is so easy to get a leakage'. And it's also a horror scenario to get leakage while trying on clothes, or that the pouch gets torn off. It does not re- ally happen, I mean it has never happened to me, but you get so anxious about it....At the same time, I have to try on the clothes to see that they suit me well and that fit over the ostomy poach.

At the same time having an ostomy makes it more difficult to find clothes that fit. Clothes are used to conceal the pouch, and this is more difficult in situations like trying on clothes in fitting rooms. It is problematic due to the potential of ruining the clothes, but also because of the fear of ruining them. In addition, our informant is concerned about revealing herself as a carrier of stigma.

\subsubsection{Requirements for Clothing and Fit}

There are some specialty products for people with disabilities, such as Velcro shoes for people with joint problems and special lingerie for ostomy with a pocket for the pouch, but our informants used these products very little. For example, they choose not to wear special underwear because it is expensive and cannot be washed at high temperatures, but also because it is not 'normal'. One of our ostomy informants uses mainly high-waist pants and a longer sweater or an over jacket. She buys clothes in regular stores, as she would rather not have to use special products in order to live the most normal life she can without feeling like a patient.

For all stoma users, it is important that there is enough of space under the clothes for the pouch. Pants with a low waistline can be beneath the pouch, and those with a high waistline can be placed over the pouch. A larger problem occurs if waistline is on the pouch and thus prevents it from being filled. These kinds of pants with a semi-high waistline are the most common today. Our informant who worked in project with other people with ostomies explained: "I have also heard that a lot of people buy maternity pants and sew the waistline so that the pouch sits where it should be". She solved the problem herself by wearing dresses or skirts combined with tights that are bit bigger than her own size to keep the poach in place.

Psoriasis arthritis gives reduced mobility, and the clothes need to be easy to put on and to take off. Thus, wearing clothes and shoes with small buttons, loops, laces or hooks was out of the question. One of our informants had problems with multiple joints, including deformed feet, which led to the need for specially made products, such as supportive shoes and insoles, but also that shoes were worn out fast. She had made a lot of mistake purchases:

You try the shoes on in the store for two seconds, and that day the foot is in that lease and then the other day you have swelling and maybe another shape in toes, and then, 'what, have I had these shoes on me'. Today I cannot get them on at all. It varies greatly. Therefore, I could start a shoe store. 


\subsubsection{Sensitivity and Materials}

The choice of materials is characterized by the demands of frequent and hard washing, and by the requirements related to the informant's desire for comfort.

Consumers with psoriasis and other eczemas have sensitive skin, and, therefore, they prefer soft clothes. Cotton, soft merino wool and viscose (also called bamboo) were preferred. They could not use the most common underwear because it has sewn rubber bands, and often decorative elements which itch, such as lace. It was also obvious that all labels were removed.

Consumers with ostomies use cotton as much as possible because it tolerates harsher laundering, whereas synthetic fabrics as well as viscose become quickly unsightly by the hard washing. The few clothes our youngest informant had in wool were for the most part valuable clothes, such as handmade clothes made by older relatives and her bunad. Bunad is a Norwegian folk costume owned by $66 \%$ of women and $21 \%$ of men, and it is used at different festive occasions (Klepp \& Laitala, 2018). It includes woollen embroidery, and other expensive fabrics, which are challenging to clean. When our informant used the valuable garment, she was especially attentive and careful so that it would not be damaged by stains. To wear it was, therefore, demanding.

\subsubsection{Replacements and Changes}

Many of our informants spoke about frequently washing clothes, which implies an increased need to have enough clean clothes available. Our retired informant with two ostomies told the following: "I have usually a set of clothes in the car, but I still have anxiety, if I'm getting leakage here and it's far to the car, so I have to walk with it, and it has happened several times". It is important to have clothing available at any given time.

Another problem that increases need for clothing is changes in weight. The informants spoke about weight changes related to cancer, problems with digestion or various medical treatments, such as cortisone and chemotherapy. One of our informants lost and then quickly regained $35 \mathrm{~kg}$, which affected which clothes fitted. It is not farfetched to think that patients who experience weight changes may have to keep several wardrobes of different sized clothes, and then alternate between them when needed. Even though this process is possible, it is not so easy in practice. As our youngest informant with ostomy explained:

You may have to wear clothes in bigger sizes again, and then you have a new round of medication....You may be a little optimistic when you are sick, thinking that now I'm not getting sick again and I can throw these clothes away. I do not want to have them because they remind me of a bad episode as well. Because you get memories connected to your clothes too that are part of your personality.
Getting rid of clothes which no longer fit and which remind the informant of bad memories highlights the social and aesthetic aspects of the clothes. The quotation clearly shows that clothes are more than just a way of hiding the body. However, in the interviews as a whole, this aspect is not emphasised. The practical and material aspects of clothing are highlighted more.

\subsection{Laundering}

Both of the conditions cause secretions from the body, and skin conditions require additional use of skin care products, which can make the clothes and bedlinen dirty. Both conditions also set requirements for how the laundry should be performed to meet today's cleanliness requirements.

\subsubsection{Oily Lotions, Flakes and Stains}

The main reason for the extra wear on clothes and bedding for people with psoriasis is due to daily use of greasy creams and ointments. All of the informants said that weekly washing of bedlinen was required. Bedsheets, lingerie and other textiles that came in contact with the creams were washed at least $60^{\circ} \mathrm{C}$. Ordinary washing in a machine was often not enough; instead, the textiles had to be rinsed beforehand to remove some of the grease so that it was not collected in the washing machine and potentially damage it. Daily use of a washing machine was common. Some also mentioned that they had to wash the machine between the laundry cycles to remove grease. Eventually, the clothes started to get a rancid smell from the ointments, which did not go away in the wash.

Underwear, nightwear and towels had to be washed after each use: "Nightwear is washed every day because if you have so much ointment on you, it gets so sticky you don't want to wear it. It is gross". The washing frequency for regular clothes varied more because the creams used during the day are less greasy. In bad periods, more severe ointments were used, and the informants attempted to use older textiles, which were then thrown out when a better period started.

In addition to the lotions, there were problems with stains of blood and pus. As one of the informants with psoriasis explained: "I had to be in the shower to take off my clothes. They were stuck in the wounds". Another big problem was her flakes: "I never use black pants, because they become white on the inside". It is difficult to estimate how often clothes are washed, but the informants thought they washed jeans after two to three days, which is twice as often as the average in Norway (Laitala, Klepp, \& Boks, 2012). However, the washing of clothing tops did not vary much from the usual, since they were washed after one to two days. The washing temperatures were close to the ones used by other Norwegians (Laitala, Klepp, \& Henry, 2018).

Several people with psoriasis and eczemas also have allergies. This means that various chemicals in clothing 
and detergents could be a problem. In addition, the skin reacts more easily to physical irritation from the clothes. There was a conflict between the need for soft clothes and their problems with chemical products, such as fabric softeners. The choice of detergents varied. Those with allergies used perfume-free agents for sensitive skin, while others tried to use the most effective and perfumed detergents to hide possible smell.

\subsubsection{Leakages, Smells and Spills}

Informants with ostomy have to prevent leakages, which is more important in public settings: "You are much more aware of the potential leakage when you are out among people, because it is subconscious, that you just keep thinking about it". It is possible to use larger pouches, but, at the same time, it will make the pouch more visible and inconvenient. An ileostomy pouch is emptied in the toilet, but it can be difficult to do this without splashing the clothes. One of our informants assumed this was a problem especially for older or less mobile people than she was.

Our informants experienced most leakages at night because they have less control while asleep. Thus, nightwear needs to be cleaned often and must withstand hard washing. Ideally, all clothing that could be exposed to leaks (lingerie, nightwear, tights, pants, dresses and skirts) should withstand at least a $600^{\circ} \mathrm{C}$ normal wash and dry cycle. In practice, the clothes could not withstand this, so our informants usually solved this by washing the laundry according to the care instructions and at a higher temperature after leakage. Our youngest informant was especially aware of this: "If there are smell stains on the leaked valve, then I wash it at once at 90 degrees".

Our informant with HS lived on disability benefits. Her HS outbreaks occurred mostly in the armpit and were fierce: "It seeps, flows pus. It smells so rotting". She said that she "smells the malodour before noticing that the lump has ruptured. Then you cannot sit in a gathering, are you crazy, it stinks so badly you think you may pass out....It's so embarrassing, especially the smell, because you can be perceived as unhygienic". In addition, smell is perceived as something that is difficult for others to overlook or get used to. Odour can, therefore, be a challenge for ostomy users as well, either because it actually smells or because they themselves are anxious about the possibility of it smelling. Our youngest informant with stoma explained the following:

It is similar to feeling as if you have not brushed your teeth one day, and you talk to somebody, trying to keep a little distance to them. That's how it is, but only constantly all the time when you're out among people.

Even an ordinary, slight smell of the body can be stigmatising in our time (Klepp, 2005). To smell as bad as our informants sometimes experience is so obviously stigma- tising that even the fear that it will happen contributes to their clothing practices. Preventing leaks is a part of the routine to hinder this, but it also affects many other aspects of daily life.

\subsection{Clothing Problems and Everyday Life}

Being well dressed and wearing clothes without stains and odours are also important prerequisites for taking part in various social activities. Our informant with atopic dermatitis worked within healthcare and had to wear a white uniform. She told of her experience with clothing:

I ended up having to change the uniform several times a day because my back bled and it bled through and was visible. It was terrible. I entered into an agreement with my colleagues that they had to tell me when it went through. But it was not a profession I could have. I had to work more even at work.

The informant who spoke most about everyday problems was a young, active student. She said the following: "With the ileostomy, just being in the park with my friends and barbequing is scary because there is not always toilet available". She had experience before:

It has actually happened once. I got a leakage and did not get into the bus, and there was no taxi that would have me either, and then my aunt from another city had to come and pick me up. So there I was standing in the city like thinking 'Help!'. Then she came fortunately, but it was not very pleasant to stand there waiting.

The experiences with ostomy were worst at the beginning, as described by our retired male informant:

It was this fear of leakage and the whole package. I was even anxious about the fear of leakage, and then I had to always have a travel route planned where I knew there were opportunities for a toilet....I started to have a small bottle in the car if I had to pee and had no place to go and brought some extra clothes and all that. Then I set up a travel route so that I knew there was a gas station or something on the road so I could plan a little ahead. So those years were very difficult, I have to say, and it was very unusual that you should wash laundry so often and so on. There were some processes to get used to.

His strategies to live with the ostomy involve controlling where he is and how he travels from place to place. He must always have clothes available to change into. Still, the anxiety is present.

Exercise poses special requirements: "You do not work out when you are like that. You do not go training with an outbreak". Informants with skin conditions have something else to think about; they are in pain and worry 
sweating may worsen the situation. For people with ostomies, the challenges are more constant, including having access to a toilet to avoid leakages and to handle the odour, which can be a problem, along with the risk of a hernia:

I'm not a very sporty person and it's partly related to the hernia. I can go walking and things like that, and it is possible to empty [the poach] in the forest, but I prefer not to, both for my own sake and for others. You try to avoid it. I rather stay at home and watch Netflix than get out to the woods.

These examples show how our informants' conditions affect their daily life. It includes their choice of occupation, their leisure time and physical activity, as well as their interactions with others. Tellingly, because of the struggles these conditions entail, our informants are more inclined to choose to stay at home.

\subsection{Financial Aspects}

Costs related to these conditions are increased by unsuccessful purchases, extra wear and tear, additional laundering and costs related to specialty and/or more expensive products. Indeed, we have already mentioned a number of aspects with financial implications for the informants and others with the same conditions, or as one of our informants with ostomy expressed it: "I do not have any problems with the quality of laundering result, the problem is the money". At the same time, laundry is one of the many extra costs in his one-man household: "there can be well over 10 washes per week, closer to $15^{\prime \prime}$.

Both of the diagnoses provide many more additional costs than those we describe; these include the cost of medicine, doctor visits, and expenses related to the adaptation of housing and transport. The overall economic situation affects their ability to buy clothing, as our retired stoma informant explained:

With the minimum pension and the support of 600 Norwegian kroner ${ }^{3}$, it is not enough to be able to build up a storage of bed linen or what it may be [that] you need. So it's always this struggle to have clean clothes.

Treatment costs must be prioritised: "Well, you have no choice but to purchase that service or product, and there will be less to eat. That's what's going on all the time; you have to prioritize everything that's about everyday living". His opinion on the expenses is clear: "It's expensive to be sick; that's the conclusion". Clothing is easily less prioritised because the treatment itself is more important. At the same time, a large supply of suitable clothes can contribute to making everyday life easier and reducing the burden of the disease.

\footnotetext{
$\overline{{ }^{3} \text { Equivalent to about } 63 \text { EUR }}$ or 74 US dollars as of September 2018.
}

\section{Discussion}

We initially asked what kinds of strategies people with these disabilities use to find clothes that fit and enable them to fit in. We will first discuss the three complicating aspects - the body, the market and the economybefore discussing the strategies our informants use to overcome these issues.

For our informants, the diseases make it harder for them to have control over their bodily secretions such as blood, dandruff, excreta, etc. Theories concerning dirt (Douglas, 1984) and the body (Mauss, 1979), as well as previous research, have shown that bodily secretions are subject to taboo and that the function of the clothes is to hide not only the body but also its secretions and its smell (Entwistle, 2000; Klepp, 2005). The secretions themselves, but especially not being able to control them, can easily become a stigma (Goffman, 1986), which is demanding for our informants. The conditions thus provide challenges in everyday life, which are about living not only with the effects of the disease, but also with the social side effects of the disease. They spend a lot of time, consideration, money and work to keep themselves and their clothes free of bodily secretions to 'pass', as Goffmann frames it, as a non-disabled person without any stigma (Goffman, 1986, p. 73).

Earlier research has shown that people with bodily deviations wear clothes both to hide the deviation but also to display it-to show that they accept themselves (Klepp \& Rysst, 2017). Our informants, however, use clothes only to conceal the signs of the condition - for example, hiding the stoma bag with a long jacket or hiding the skin rash with long-sleeved and high-necked clothes. The most important way that the clothes are used to conceal the disability is through hard and frequent laundering. Our informants want to hide their lack of control over their bodily secretions and the malodour, and there is no indication that the informants would even consider choosing an opposite strategy. The possibility to keep the clothes clean is more important than the other requirements for clothing.

Clothes are also used to make the body look beautiful and make us look attractive and sexy. These aspects of the body and clothing were given low priority. We do not have enough material to discuss these aspects of the clothes in detail. However, we have some examples that the aesthetic aspects are prioritised by our informants in certain contexts, such as at work and parties. The aesthetic aspects are given especially little priority at home and at night. The fact that our informants can wear simpler clothing at home makes staying at home so much easier.

The diseases set requirements for clothing. They should not chafe already sensitive skin, nor should they squeeze the ostomy pouch while holding it in place. Both the diseases and their medication contribute to the bodies deviating from the ideal body and to the body size and 
shape potentially changing frequently. Therefore, finding clothes and shoes that fit is more difficult, and in addition, they need to be replaced more often. At the same time, they have reduced possibilities to try on clothes, and the result is often mistake purchases.

The clothing market is characterized by a lack of information but, even more alarmingly, also by faulty information about sizes and materials (Hardin, Wilson, Dhandapani, \& Dhende, 2009; Laitala, Hauge, \& Klepp, 2012). This makes it harder to find clothes that fit. On the one hand, several informants had personal experiences with materials that were suitable, but on the other hand, the labelling of viscose as bamboo was confusing. Viscose is a soft material, but it is also weak when wet; thus, it is easily damaged in laundering. Many of our informants knew this, but they did not now that bamboo is viscose. Thus, they acquired clothing in material that does not tolerate the harsh laundering they rely on.

We have so far presented our informant's stories about their own practices and reasons for them. We also tried to ask their thoughts about how clothes could help make their illnesses and lives easier. They had not really thought about it, which is completely in line with previous literature. There is little research on how clothing and textile materials can contribute positively, although some studies can be found, such as merino wool can be used to treat skin problems (Su et al., 2017) or that some clothes with different materials smell very different after reacting with sweat (Klepp, Buck, Laitala, \& Kjeldsberg, 2016; McQueen, Laing, Delahunty, Brooks, \& Niven, 2008). A more proactive attitude towards clothing consumption requires more knowledge, improved private economy and a better market.

The diseases also contributed to lower incomes for those who could not work or who could only work part time; the diseases also increased expenses for treatment and in daily life. Increased washing frequency, a larger number of mistake purchases and more damaged clothes are all factors contributing to increased clothing costs. A poorer economic situation leads to clothing having a lower priority, which, in turn, contributes to extra work and/or a reduced comfort level.

The different strategies the informants use to live with these challenges can be divided into three different categories. The first strategies are linked to the relationship between the clothes and the body. Clothes are used to conceal the disability; at other times, they are used to minimize the practical consequences of the illnesses. In everyday life, simple clothes are used that can tolerate hard and frequent washing. Nicer clothes were rarely used, and time and effort were invested in order not to damage them. The informants were less concerned with how the clothes could work positively to help ease the illness and improve everyday life; they were more concerned about how the clothes would not make things worse.

The second strategies are related to the connection between the clothes they wanted and the market; they are about how to access usable clothes and other textiles. They used mainly the mass market products, but not in a standardized manner. They opted out for special products for economic reasons and because they wanted to be as ordinary as possible, which is in line with earlier studies (Klepp \& Rysst, 2017; Lamb, 2001; Thorén, 1996). Some customization took place by using clothes that were intended for other consumer groups-e.g., women using men's trousers or using maternity clothing while not pregnant. These strategies did not include so much sewing, but rather cutting off labels, rubber bands and other things that caused irritation. Many had not found a good solution for the problem of not being able to try on clothes, other than taking the burden of mistake purchases themselves.

The last strategy has to do with economics. They had different ways of reducing expenses, such as wearing old clothes when the disease was bad and buying the cheapest possible clothes from the regular clothing stores, even when these were not optimal. In summary, we can say that their main strategy was to reduce the requirements for their own appearance, but not to the body odours. If they were unable to appear decent, as at least odourless and stain free, they reduced their participation in social life, such as in work, or in leisure and physical activities. Not participating in such social activities is a strategy with major consequences for social inclusion, as it can potentially lead to social exclusion.

\section{Conclusions}

The ostomy and various chronic skin conditions have had a great effect on the everyday lives of our informants. They affect many aspects of clothing consumption, such as how purchases take place, which clothes fit, how much clothing they need, and in what way and how often they are washed. The conditions also make them avoid situations where they cannot be appropriately dressed.

Consumers with disabilities face various problems as clothing consumers, since they must search for clothing that meets their social, practical and technical requirements for functionality, comfort and aesthetics. The strategies are linked to the relationship between the clothes and the body. In some situations, clothes are used to conceal the disability, and at other times, they are used to minimize the disability's practical consequences. Other strategies are related to the connection between the clothes and the market; they are about how to get customized clothes and other textiles, such as bedding. The last strategy has to do with economics, as many people with disabilities have reduced income and have to try to get additional expenses covered by existing support schemes.

There is room for variation within the dress code, which would make it possible to adapt clothing despite the challenges that the body, the economy and the market set. This applies mainly to how the clothes look like. 
There is much less acceptance for malodours and stains. The relationship between cleanliness and dignity is central for not only well-being, but also social inclusion, but this is little discussed in clothing research.

There is generally little knowledge about clothes in everyday life for people with different bodies, socioeconomic levels and physical and mental challenges. This study addressed only few informants and conditions, and the results given are, thus, just a starting point for future research on disabilities and clothing consumption. Further research should look at other diagnoses and conditions, and focus on women, men and children separately. We also believe there is an unexplored field at the intersection between medical research and clothing research. Textiles have different properties in terms of humidity, temperature regulation and resistance to odours; they could, therefore, be used more actively in treating these skin conditions as well as giving people with different bodies a worthy and comfortable life. To achieve this, we need to gain knowledge across disciplines and about physical and mental aspects of living. Clothing, appearance and cleanliness are important for everyone for practical reasons, but also for self-esteem, self-respect and participation in society. Studies of clothing can thus contribute to discussions about health and quality of life.

\section{Acknowledgements}

We would like to thank the patient organizations for all the help during research, and our informants for sharing their experiences so openly with us. We are also grateful to the anonymous peer-reviewers whose comments improved this article significantly.

\section{Conflict of Interests}

The authors declare no conflict of interest.

\section{References}

Augustin, M., Kruger, K., Radtke, M. A., Schwippl, I., \& Reich, K. (2008). Disease severity, quality of life and health care in plaque-type psoriasis: A multicenter cross-sectional study in Germany. Dermatology, 216(4), 366-372. http://dx.doi.org/10.1159/ 000119415

Barbarot, S., Auziere, S., Gadkari, A., Girolomoni, G., Puig, L., Simpson, E. L., . . . Eckert, L. (2018). Epidemiology of atopic dermatitis in adults: Results from an international survey. Allergy, 73(6), 1284-1293. http://dx.doi.org/10.1111/all.13401

Berger, K., Ehlken, B., Kugland, B., \& Augustin, M. (2005). Cost-of-illness in patients with moderate and severe chronic psoriasis vulgaris in Germany. JDDG: Journal der Deutschen Dermatologischen Gesellschaft, 3(7), 511-518. http://dx.doi.org/10.1111/j.16100387.2005.05729.x

Berghs, M. J., Atkin, K. M., Graham, H. M., Hatton, C., \&
Thomas, C. (2016). Implications for public health research of models and theories of disability: A scoping study and evidence synthesis. Public Health Research, 4(8). http://dx.doi.org/10.3310/phr04080

Bjerck, M., Klepp, I. G., \& Skoland, E. (2014). Made to Fit: Å kle en avvikende kropp-Handikap og klær [Made to fit: Dressing a deviant body-Handicap and clothing]. Oslo: Consumption Research Norway (SIFO). Retrieved from www.hioa.no/extension/hioa/design/ hioa/images/sifo/files/file79516_oppdragsrapport_ 9-2013_web.pdf

Brown, H., \& Randle, J. (2005). Living with a stoma: A review of the literature. Journal of Clinical Nursing, 14(1), 74-81. http://dx.doi.org/10.1111/j.13652702.2004.00945.x

Cima, R. R. (2018). Parastomal hernia. UpToDate. Retrieved from www.uptodate.com/contents/para stomal-hernia

Classen, C., Howes, D., \& Synnott, A. (1994). Aroma: The cultural history of smell. London: Routledge.

Coons, S. J., Chongpison, Y., Wendel, C. S., Grant, M., \& Krouse, R. S. (2007). Overall quality of life and difficulty paying for ostomy supplies in the veterans affairs ostomy health-related quality of life study: An exploratory analysis. Medical Care, 45(9), 891-895. http://dx.doi.org/10.1097/MLR.0b013e318074ce9b

de Korte, J., Sprangers, M. A., Mombers, F. M., \& Bos, J. D. (2004). Quality of life in patients with psoriasis: A systematic literature review. Journal of Investigative Dermatology Symposium Proceedings, 9(2), 140-147. http://dx.doi.org/10.1046/j.10870024.2003.09110.x

Douglas, M. (1984). Purity and danger: An analysis of the concepts of pollution and taboo. London: Ark Paperbacks.

Dubertret, L., Mrowietz, U., Ranki, A., Van De Kerkhof, P., Chimenti, S., Lotti, T., . . . Survey, E. P. (2006). European patient perspectives on the impact of psoriasis: The EUROPSO patient membership survey. British Journal of Dermatology, 155(4), 729-736. http://dx.doi.org/10.1111/j.13652133.2006.07405.x

Ellis, C. N., Drake, L. A., Prendergast, M. M., Abramovits, W., Boguniewicz, M., Daniel, C. R., . . . Tong, K. B. (2002). Cost of atopic dermatitis and eczema in the United States. Journal of the American Academy of Dermatology, 46(3), 361-370. http://dx.doi.org/ $10.1067 / \mathrm{mjd} .2002 .120528$

Entwistle, J. (2000). The fashioned body: Fashion, dress, and modern social theory. Cambridge: WileyBlackwell.

Freeman, C. M., Kaiser, S. B., \& Wingate, S. B. (1985). Perceptions of functional clothing by persons with physical disabilities: A social-cognitive framework. Clothing and Textiles Research Journal, 4(1), 46-52. http://dx.doi.org/10.1177/0887302X8500400107

Frykman, J., \& Löfgren, O. (1994). Det kultiverte mennesket [Culture builders: A historical anthropology of 
middle-class life]. Oslo: Pax.

Goffman, E. (1986). Stigma: Notes on the management of spoiled identity. New York, NY: Simon \& Schuster.

Gooszen, A., Geelkerken, R., Hermans, J., Lagaay, M., \& Gooszen, H. (2000). Quality of life with a temporary stoma. Diseases of the Colon \& Rectum, 43(5), 650-655. http://dx.doi.org/10.1007/BF02235581

Grue, J. (2015). Disability and discourse analysis. Surrey: Ashgate.

Hardin, I. R., Wilson, S. S., Dhandapani, R., \& Dhende, V. (2009). An assessment of the validity of claims for "Bamboo" fibers. AATCC Review, 9(10), 33-36.

Kabel, A., Dimka, J., \& McBee-Black, K. (2017). Clothingrelated barriers experienced by people with mobility disabilities and impairments. Applied Ergonomics, 59, 165-169. http://dx.doi.org/10.1016/ j.apergo.2016.08.036

Kaiser, S. B. (1997). The social psychology of clothing. Symbolic appearances in context (2nd ed.). New York, NY: Fairchild publications.

Klepp, I. G. (2003). Fra rent til nyvasket: Skittent og rent tøy [Clean to new-washed: Dirty clothesClean habits]. Oslo: SIFO. Retrieved from www.hioa. no/extension/hioa/design/hioa/images/sifo/files/file 48508_fagrapport2003-2.pdf

Klepp, I. G. (2005). The meaning of cleanliness: Modern demonstrations of female purity. In G. Hagemann \& H. Roll-Hansen (Eds.), Twentieth-century housewives: Meanings and implications of unpaid work (pp. 191-216). Oslo: Unipub.

Klepp, I. G. (2007). Patched, louse-ridden, tattered: Clean and dirty clothes. Textile: Journal of Cloth and Culture, 5(3), 254-275. http://dx.doi.org/10.2752/ $175183507 \times 249459$

Klepp, I. G., Buck, M., Laitala, K., \& Kjeldsberg, M. (2016). What's the problem? Odor-control and the smell of sweat in sportswear. Fashion Practice, 8(2), 296-317. http://dx.doi.org/10.1080/17569370.2016.1215117

Klepp, I. G., \& Laitala, K. (2018). Nisseluelandet-The impact of local clothes for the survival of a textile industry in Norway. Fashion Practice, 10(2), 171-195. http://dx.doi.org/10.1080/17569370.2018.1458497

Klepp, I. G., \& Rysst, M. (2017). Deviant bodies and suitable clothes. Fashion Theory, 21(1), 79-99. http://dx.doi.org/10.1080/1362704X.2016.1138658

Kratz, G., Soderback, I., Guidetti, S., Hultling, C., Rykatkin, T., \& Soderstrom, M. (1997). Wheelchair users' experience of non-adapted and adapted clothes during sailing, quad rugby or wheel-walking. Disability and Rehabilitation, 19(1), 26-34. http://dx.doi.org/ 10.3109/09638289709166442

Laitala, K., Hauge, B., \& Klepp, I. G. (2012). "Sizes are arbitrary, you can't trust them". A study of the relationship between size labeling and actual clothing sizes. In P. McNeil \& L. Wallenberg (Eds.), Nordic fashion studies (pp. 201-220). Stockholm: Axl books.

Laitala, K., Klepp, I. G., \& Boks, C. (2012). Changing laundry habits in Norway. International Jour- nal of Consumer Studies, 36(2), 228-237. http:// dx.doi.org/10.1111/j.1470-6431.2011.01081.x

Laitala, K., Klepp, I., \& Henry, B. (2018). Does use matter? Comparison of environmental impacts of clothing based on fiber Type. Sustainability, 10(7), 2524. http://dx.doi.org/10.3390/su10072524

Lamb, J. M. (2001). Disability and the social importance of appearance. Clothing and Textiles Research Journal, 19(3), 134-143. http://dx.doi.org/ 10.1177/0887302X0101900304

Lamb, J. M., \& Kallal, M. J. (1992). A conceptual framework for apparel design. Clothing and Textiles Research Journal, 10(2), 42-47. http://dx.doi.org/ $10.1177 / 0887302 \times 9201000207$

Larssen, V. L., \& Bry, K. (2001). Såpe: Kledd med Frelsesarmeen [Soap: Dressed with the Salvation Army]. Oslo: Frelsesarmeen.

Lurie, A. (1981). The language of clothes. New York, NY: Random House.

Mauss, M. (1979). Sociology and psychology: Essays. London: Routledge \& Kegan Paul.

McQueen, R., Laing, R. M., Delahunty, C. M., Brooks, H. J. L., \& Niven, B. E. (2008). Retention of axillary odour on apparel fabrics. Journal of the Textile Institute, 99(6), 515-523. http://dx.doi.org/10.1080/ 00405000701659774

Moradi, M., Rencz, F., Brodszky, V., Moradi, A., Balogh, O., \& Gulacsi, L. (2015). Health status and quality of life in patients with psoriasis: An Iranian crosssectional survey. Archives of Iranian Medicine, 18(3), 153-159. http://dx.doi.org/0151803/aim.004

Mustonen, A., Mattila, K., Leino, M., Koulu, L., \& Tuominen, R. (2014). Psoriasis causes significant economic burden to patients. Dermatology and Therapy, 4(1), 115-124. http://dx.doi.org/10.1007/s13555-0140053-2

NAV. (2018). Basic benefit. Norwegian Labour and Welfare Administration. Retrieved from www.nav.no/ en/Home/Benefits+and+services/Relatert+informas jon/basic-benefit

Navarini, A. A., Laffitte, E., Conrad, C., Piffaretti, P., Brock, E., Ruckdaeschel, S., \& Trüeb, R. M. (2010). Estimation of cost-of-illness in patients with psoriasis in Switzerland. Swiss Medical Weekly, 140(5), 85-91.

Nutten, S. (2015). Atopic dermatitis: Global epidemiology and risk factors. Annals of Nutrition \& Metabolism, 66(1), 8-16. http://dx.doi.org/10.1159/ 000370220

Poyner, T., Wall, A., Adnitt, P., \& Menday, A. (1999). Economic impact of psoriasis treatment on the patient and on the National Health Service. Journal of Dermatological Treatment, 10(1), 25-29. http:// dx.doi.org/10.3109/09546639909055907

Proba. (2017). Gjennomgang av grunnstønadsordningen [Review of the basic benefit scheme] (Rapport no. 2017-12). Oslo: PROBA samfunnsanalyse. Retrieved from proba.no/app/uploads/sites/4/rapport2017-12-gjennomgang-av-grunnstonad.pdf 
Proena, A., \& Rydelius, L. (2015). Erfarenheter av att leva med stomi efter kolo-/rektalcancer: En litteraturstudie [Experiences from living with an ostomy after colorectal/rectal cancer] (Unpublished Bachelor thesis). Faculty of Medicine, Umeå University, Sweden. Retrieved from urn.kb.se/resolve?urn= urn:nbn:se:umu:diva-118720

Roos, G., Laitala, K., Klepp, I. G., Austgulen, M. H., \& Borgeraas, E. (2018). Kartlegging av ekstrautgifterUtgifter til mat for personer med cøliaki og andre diagnosegrupper og til klær og sko for personer med sykdommer eller lidelser som fører til ekstraordinær slitasje på klær eller sengetø [Mapping of additional expenses: Food expenses for people with celiac disease and other diagnosis groups and expenses for clothing and shoes for people with diseases or disorders that lead to extraordinary wear on clothes or bedding]. Oslo: SIFO. Retrieved from www.hioa.no/content/download/147475/4123820/ file/OR\%206\%20-\%202018\%20Ekstrautgifter.pdf

Sachdeva, S., Gupta, V., Amin, S. S., \& Tahseen, M. (2011). Chronic urticaria. Indian Journal of Dermatology, 56(6), 622-628. http://dx.doi.org/10.4103/00195154.91817

Shakespeare, T. (2018). Disability-The basics. London: Routledge.

Shove, E. (2003). Comfort, cleanliness and convenience: The social organization of normality. Oxford: Berg.

Siegfried, E. C., \& Hebert, A. A. (2015). Diagnosis of atopic dermatitis: Mimics, overlaps, and complications. Journal of Clinical Medicine, 4(5), 884-917. http://dx.doi.org/10.3390/jcm4050884

Sohn, S., Schoeffski, O., Prinz, J., Reich, K., Schubert, E., Waldorf, K., \& Augustin, M. (2006). Cost of moderate to severe plaque psoriasis in Germany: A multicenter cost-of-illness study. Dermatology, 212(2), 137-144. http://dx.doi.org/10.1159/000090654

Su, J. C., Dailey, R., Zallmann, M., Leins, E., Taresch, L., Donath, S., . . . Lowe, A. J. (2017). Determining effects of superfine sheep wool in infantile eczema (DESSINE): A randomized paediatric crossover study. British Journal of Dermatology, 177(1), 125-133. http://dx.doi.org/10.1111/bjd.15376

Thorén, M. (1996). Systems approach to clothing for disabled users. Why is it difficult for disabled users to find suitable clothing. Applied Ergonomics, 27(6), 389-396. http://dx.doi.org/10.1016/S00036870(96)00029-4

Weiss, S. C., Kimball, A. B., Liewehr, D. J., Blauvelt, A., Turner, M. L., \& Emanuel, E. J. (2002). Quantifying the harmful effect of psoriasis on health-related quality of life. Journal of the American Academy of Dermatology, 47(4), 512-518. http://dx.doi.org/ 10.1067/mjd.2002.122755

WHO. (2011). World report on disability. Malta: The World Health Organization. Retrieved from whqlibdoc.who.int/publications/2011/97892406852 15_eng.pdf?ua=1

WHO. (2016). Global report on psoriasis. Geneva: The World Health Organization. Retrieved from apps.who.int/iris/bitstream/handle/10665/204417/ 9789241565189_eng.pdf;jsessionid=A4BF0218A4A5 83EBD8359D35797F4868? sequence $=1$

Zachariae, H., Zachariae, R., Blomqvist, K., Davidsson, S., Molin, L., Mork, C., \& Sigurgeirsson, B. (2002). Quality of life and prevalence of arthritis reported by 5,795 members of the Nordic Psoriasis Associations. Data from the Nordic Quality of Life Study. Acta Dermato Venereologica, 82(2), 108-113. http://dx.doi.org/ $10.1080 / 00015550252948130$

\section{About the Authors}

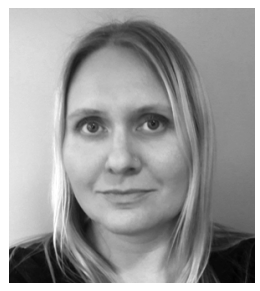

Kirsi Laitala is a Senior Researcher at Consumption Research Norway-SIFO at Oslo Metropolitan University, where she has been working with textile and consumer research since 2001 . Her educational background is in textile engineering and she holds a PhD in Product Design. Laitala's main research areas are sustainability, clothing consumption and vulnerable consumers. She uses interdisciplinary research methods that often combine material studies of textiles with consumer studies, and qualitative methods with quantitative surveys.

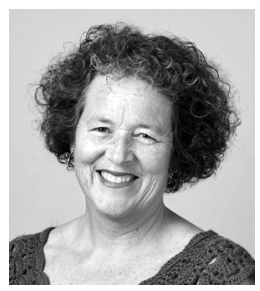

Ingun Grimstad Klepp is Research Professor at Consumption Research Norway-SIFO, Oslo Metropolitan University. She has a PhD and Magister atrium in ethnology from University of Oslo. Her interest lies in the connection between material and cultural aspects of clothing and consumption. Klepp has worked mostly with environmental issues but is also interested in clothes in relation to democracy, integration and health. She has written several books and articles about wool, knitting, laundry and clothing. She uses a lot of time on popular dissemination and discussions. 